\title{
MANIFESTAÇÕES SOCIAIS E NOVAS MÍDIAS: a construção de uma cultura contra-hegemônica
}

\author{
Paulo Rodrigues Gajanigo* \\ Rogério Ferreira de Souza * *
}

\begin{abstract}
O artigo analisa algumas manifestações sociais que surgiram pelo mundo a partir de 2008, em especial no Egito, na Espanha, nos EUA, no Chile e no Brasil. O nosso interesse está no impacto, nessas manifestações, do uso das redes sociais, já razoavelmente inseridas num contexto de intensa mediação na comunicação entre manifestantes e na opinião pública em geral. Analisamos dois aspectos: o impacto na organização desses movimentos e o uso cada vez mais central das imagens como forma de comunicação. Com a preocupação de identificar pontos de novidade mais do que analisá-los profundamente, indicamos que há interessantes possibilidades de luta contra-hegemônica a partir do uso extensivo e intensivo das mídias sociais, o que se dá pela busca da democracia radical e pelo uso crítico da imagem. PaLavras-chave: Internet. Mídias sociais. Hegemonia. Movimentos sociais. Política.
\end{abstract}

Neste artigo, propomo-nos a avaliar, a partir das manifestações que ocorreram a partir de 2008, quando já se consolidara o uso das redes sociais virtuais, ${ }^{1}$ como a mediação de tais redes tem impactado a dinâmica das manifestações. É evidente que, por ser um processo recente e pelo escopo de um artigo, esses impactos não poderão ser avaliados em deta-

\footnotetext{
* Doutor em Ciências Sociais. Professor da Universidade Federal Fluminense (UFF). Líder do Núcleo de Estudos da Cultura no Capitalismo Tardio. Membro do Núcleo Interdisciplinar de Estudos e Pesquisas sobre Marx e Marxismo (Niep-Marx).

Rua José do Patrocínio, ${ }^{\circ}$ 71, Centro. CEP: 28010-385. Campos dos Goytacazes - Rio de Janeiro - Rio de Janeiro. gajanigo@gmail.com

** Doutor em Ciências Sociais. Professor Programa de Pósgraduação em Sociologia do Instituto Universitário de Pesquisas do Rio de Janeiro (IUPERJ-UCAM). Coordenador do Laboratório de Estudos da Cidade e Cultura, IUPERJ-UCAM (LECC), junto ao CNPq.

Praça Pio X, n. 7. Cep: 22040-020. Candelária - Rio de Janeiro - Rio de Janeiro. rogeriosouza@iuperj.br

${ }^{1}$ Como sugere Ilser Scherer-Warren (2006), faz-se necessário, frente ao numeroso conjunto de denominações, categorizações e tipologias sobre redes sociais, mídias sociais, redes de relacionamentos etc., definir a categoria de análise mais próxima do objeto de estudo sugerido. Assim, optamos por redes sociais virtuais, por entender que essa terminologia englobaria um conjunto de atores conectados no ciberespaço com interesses diversos, como blogs, sites, redes de relacionamentos, redes de entretenimento, entre outras denominações. Ao contrário de rede de movimento social, em que a objetividade dos atores interligados já está colocada e definida
}

lhe. Antes, queremos destacar dois pontos que ajudam nas problematizações futuras do tema. Primeiro, trataremos de como as novas tecnologias de comunicação passaram a exercer papel importante na mediação e organização das manifestações sociais, buscando destacar o sentido do "novo" nessas manifestações, através de coletivos em redes; ${ }^{2}$ segundo, abordaremos o impacto, nas formas de comunicação e publicização, particularmente da centralidade dos usos das imagens como forma de expor as bandeiras e fortalecer politicamente a luta dos sujeitos de tais manifestações. Nossa preocupação ao avaliar esses impactos, ainda que inicialmente, é pensar as possibilidades e impossibilidades existentes na configuração da uma luta contra-hegemônica. ${ }^{3}$

${ }^{2}$ Os coletivos em redes caracterizam as conexões, "numa primeira instância comunicacional, instrumentalizada através de redes técnicas, de vários atores ou organizações, que buscam difundir informações e buscar apoio solidário” (Scherer-Warren, 2006, p.216).

${ }^{3}$ Antes, porém, cabe esclarecer que o sentido dado à expressão "luta contra-hegemônica" é proveniente do pensamento gramsciano e se expressa em lutas sociais, econômicas e culturais, de uma posição ideológica antagônica de classe, estabelecendo diferenças frente ao modo de cultura vigente, ou hegemônico. A contra-hegemonia, nesse caso, seria um movimento de questionamento de valores políticos, sociais, culturais e econômicos. Gramsci não usa o termo contra-hegemonia, mas, seguindo autores inspira- 
Para tanto, dialogaremos com uma visão mais pessimista sobre o uso amplo das mídias sociais e suas consequências políticas. No que diz respeito ao formato, pode-se argumentar que esses movimentos organizados pelas redes sociais virtuais são inócuos, já que eles estariam fadados à fragmentação e ao espontaneísmo, o que constitui um obstáculo à luta política de fato. Aqui se contrapõem esses movimentos aos movimentos clássicos da classe trabalhadora, que fazem uso de instituições políticas, como partidos, sindicatos e associações. As redes sociais virtuais, portanto, não se enquadram nas formas organizativas experimentadas até agora. Aqueles que apontam exclusivamente para essas formas consagradas, ao pensar a eficácia das mobilizações, resistem a ver uma capacidade de luta contra-hegemônica com a mediação das redes virtuais. De fato, as novas mobilizações deslocam o local tradicional do enunciado na sociedade capitalista, redimensionando a importância da função organizadora das instituições políticas. Por trás dessa perspectiva, há uma visão mais geral de que as relações criadas pelas redes virtuais são de natureza frágil, o que impediria os vínculos fortes necessários à política. É o que defendeu recentemente Malcolm Gladwell em $A$ revolução não será tuitada (2010). ${ }^{4}$

No sentido midiático, a larga bibliografia sobre o caráter alienante da mediação imagética das relações sociais nos indica que a generalização do uso das novas tecnologias de comunicação e das redes sociais virtuais aprofundaria a espetacularização das relações sociais (e o caráter conservador e passivo desses sujeitos, denunciado por Guy Debord) e, por\& tanto, impediria um uso político eficaz para aqueles que buscam a democratização da sociedade. Além disso, a sociabilidade mediada dos em seu pensamento, usamos o termo para tratar da resistência ao estabelecimento da hegemonia e da busca por uma alteração da ordem vigente. E um processo historicamente longo e requer uma reforma moral e cultural que possibilite a condução de um grupo ou bloco de classe ao poder (ver Gramsci, 2007; Coutinho, 2007; Moraes, 2010)

${ }^{4}$ Há uma interessante crítica ao pessimismo de Gladwell feita por Andy Merrifield (2011). pelas redes sociais virtuais tem fortalecido, no primeiro impacto, a fluidez e efemeridade dos produtos das relações (imagens, mensagens). André Lemos (2007, p. 38) afirma que a cibersociabilidade forma uma:

\begin{abstract}
[...] subjetividade exteriorizada, desterritorializada, efêmera, empática [que] cria novos formatos sociais que visam compartilhar, à distância e em tempo real, a vida como ela é. A vida comum transformase em algo espetacular (atrai e prende o olhar) e ao mesmo tempo especular (reflete o olhar, o espelho). Não há histórias, aventuras, enredos complexos ou desfechos.
\end{abstract}

No entanto, o que vimos, nesses últimos anos, foi um uso positivo dessas novas tecnologias de informação e comunicação a serviço de um coletivo em rede (Scherer-Werren, 2006) no ciberespaço, na construção do movimento político. Se essa sociabilidade ganha em imediatismo, fluidez, efemeridade e fragmentação, interessa-nos saber como esses atributos estão sendo usados politicamente e como são enfrentados os obstáculos à politização.

\section{A ORGANIZAÇÃO POLÍTICA MEDIA- DA PELAS REDES SOCIAIS VIRTU- AIS}

Inúmeros autores ${ }^{5}$ que estudam o processo de globalização e os movimentos sociais postulam que, a partir da década de 1990, com a expansão da Internet pelo mundo, foram surgindo novas formas de comunicação entre os indivíduos, como os blogs, as mídias alternativas e os diferentes sites de relacionamento (Orkut, Facebook, Twitter, entre outros), engendrando, assim, uma cibercultura, como classifica Lévy (2011). Tal mudança foi consequência do movimento social iniciado nos anos de 1970, que tinha como propósito a democratização e a universalização do uso do compu-

${ }^{5}$ Dentre eles, podem-se destacar: Manuel Castells (2010); Pierre Lévy (2011); Maria da Gloria Gohn (2007); Nestor García Canclini (2009); Scherer-Warren (2006), Denis Moraes $(2008,2010)$, entre outros. 
tador pessoal e da linguagem informacional. ${ }^{6}$

Segundo o autor, a partir desse momento "[...] o significado social da informática foi completamente transformado" (Lévy, 2011, p. 127), pois possibilitou que um número muito maior de pessoas tivesse acesso a esse meio técnico e de comunicação. Nesse sentido, o autor destaca que a disponibilidade da informática pessoal não foi fruto de uma decisão governamental nem de uma multinacional poderosa, mas de um "[...] movimento social visando à reapropriação, em favor dos indivíduos, de uma potência técnica que até então havia sido monopolizada.” (Lévy, 2011, p. 127).

Os anos de 1990 também foram um período marcado por inúmeras manifestações e movimentos sociais antiglobalização, que reocuparam os espaços públicos em vários países. Tais movimentos seriam uma resposta ao agravamento da crise financeira global, que impôs medidas severas de controle dos gastos públicos sociais, além de um alto índice de desemprego em grandes economias, como a dos EUA e a de países da Europa.

Assim como Pierre Lévy, Manuel Castells também destacou que o mundo, a partir da década de 1970, passou a experimentar uma nova forma de sociabilidade, de comunicação e integração política, social e econômica, o que foi denominado pelo autor de "sociedade em rede". Castells (2001b) observou que, no bojo das transformações tecnológicas que deram amplitude à globalização, possibilitou-se, também, o surgimento de novas manifestações e movimentos sociais no cenário político internacional, que exigiam mudanças no discurso político e cujo conteúdo passava das questões socioeconômicas da desigualdade social para a desigualdade cultural, ou seja, o discurso da

${ }^{6}$ Segundo Lévy (2011), o processo teve início nos anos de 1970 , com o movimento social surgido na Californiana, denominado Computers for the People, que tinha como objetivo levar a linguagem e a utilização dos computadores para todos os indivíduos, tirando-os do domínio dos especialistas das grandes corporações e instituições burocratas. Mas, como afirma Lévy, isso não impediu que a indústria não absorvesse esse ideal, transformando-o em um consumo de massa e aumentando significativamente a produção de softwares e computadores pessoais. diferença. Grande parte desses movimentos buscou incorporar, em seus discursos políticos, a valorização das identidades e suas singularidades, do direito à expressão de novas ou diferentes formas de ver e estar no mundo e de uma política de tolerância às diferenças.

Nesse processo, boa parte dos partidos políticos, em sua maioria partidos de esquerda, procurou incorporar discursivamente, em suas plataformas partidárias, as políticas de tolerância às diferenças sociais, culturais e identitárias. Em certo sentido, uma nova ordem democrática foi estabelecida no âmbito das demandas sociais e culturais, na qual um conjunto maior de exigências foi imposto ao modelo de democracia representativa partidária; um sentido de democracia mais dilatado e abrangente, porém, mais fragmentado. Como salienta Maria da Gloria Gohn (2007, p. 124), ao tratar dos novos movimentos sociais: “[...] são novos porque não têm uma clara base classista, como nos velhos movimentos operários ou camponeses; e porque não têm um interesse especial de apelo para nenhum daqueles grupos. São interesses difusos”.

Isso, no entanto, não foi forte o suficiente para deslocar o local do enunciado determinante, ou seja, as instituições políticas (partidos, sindicatos, associações etc...). Elas ainda se localizavam como agentes do enunciado e suas estruturas como os locais dos enunciados predominantes. Assim sendo, mesmo com as grandes manifestações antiglobalização que marcaram os anos de 1990 até os primeiros anos da década de 2000, a lógica das ações sociais dos movimentos, ao fim e ao cabo, em grande parte, permaneceu pautada pela lógica das organizações políticas - filiação partidária, filiação sindical, eleições representativas, governabilidade com maioria no parlamento etc. Na América Latina, vimos como o caldo político dos movimentos antiglobalização, expressados, por exemplo, no Fórum Social Mundial, foram capitaneados pelos partidos de esquerda a partir de 2002, com a eleição vários presidentes vinculados aos partidos de 
esquerda, como é o caso do Brasil, com a eleição e reeleição de Lula. Assim também foi na Argentina, na Venezuela, na Bolívia e no Peru. Grande parte desses presidentes eleitos e seus partidos participou do Fórum Mundial Social e dos movimentos antiglobalização. Suas plataformas e promessas de governo se pautaram em um viés contra-hegemônico ao capitalismo mundial e às políticas econômicas dos organismos internacionais - Fundo Monetário Internacional, Banco Mundial etc. As transformações sociais e as demandas por direitos identitários, que teriam sido a tônica política desse período, seriam transformadas em plataformas de políticas partidárias discutidas no âmbito parlamentar, juntamente com questões de Estado e Economia. Seria, nos termos de Gramsci, uma Revolução Passiva, pois, apesar das grandes propostas sociais, em detrimento da política econômica anteriormente prioritária, faltou uma radicalidade nas ações, capaz de transformar o Estado em um Estado renovado, pois ela manteve o seu caráter inacabado, já que as alianças com os setores tradicionais e conservadores e com a alta burguesia financeira foram mantidas. O que se deu, grosso modo, foi um deslocamento do foco discursivo, da economia para o social. ${ }^{8}$

Surge, nesse período, o que Francisco de Oliveira (2007) aponta como a "A Era da indeterminação", pois, apesar das conquistas políticas da esquerda partidária e a mudança discursiva para o campo das demandas sociais, a crise econômica e o sentimento de incerteza e de insatisfação não foram dissipados, principalmente pelos jovens. É nesse contexto e em i paralelo a tantas mudanças nos rumos políti$\therefore$ cos e nas demandas dos movimentos sociais, సे que vimos surgir inúmeras manifestações,

7 Na Argentina, foi eleito Néstor Kirchner em 2003 pelo Partido Justicialista; na Venezuela, Hugo Chaves em 2002 reposto ao poder após Golpe de Estado; no Peru, Alejandro Toledo pelo Partido Peru Possível, em 2001; na Bolívia, Evo Morales, em 2006, do Partido Movimento Para o Socialismo.

${ }^{8}$ Para um aprofundamento sobre o tema da Revolução Passiva, ver Gramsci, "Cadernos do Cárcere - Maquiavel notas sobre o Estado e a Política”. (2007a); e Lincoln Secco em "Gramsci e a Revolução" (2006). principalmente de jovens insatisfeitos com as condutas políticas tomadas pelos governos democráticos e com o próprio modelo de democracia participativa. Munidos de uma inventividade própria da juventude e de um ferramental tecnológico capaz de unir grupos de indivíduos heterogêneos, esses movimentos passaram a tomar os espaços públicos como palco de manifestações contra os modelos de democracia participativa, incapaz de minimizar a desigualdade social e impedir o avanço do capitalismo financeiro no mundo globalizado.

Desde início, o caráter contra-hegemônico esteve presente nesses movimentos, principalmente com as mobilizações em torno da repulsa à globalização e ao modelo neoliberal dos anos de 1990, que instituíam, hegemonicamente, um consenso economicista à vida social, um consenso moral e cultural, ideologicamente propagado pelos organismos internacionais. Tais organismos - Fundo Monetário Internacional, Organização Mundial do Comércio, Banco Mundial e o G8 (Grupo que reunia os oito países mais ricos) - defendiam uma agenda de política global com forte ênfase no livre comércio internacional, na globalização econômica, nas finanças e na desregulamentação do Estado, e foram eles os principais focos das manifestações.

As formas de manifestação se mesclaram em desobediência civil e ações lúdicas, carnavais e protestos, atividades em redes sociais virtuais, sites e blogs, ou em ações diretas nos espaços públicos. Dentre esses primeiros movimentos jovens, destacam-se o Reclaim the Streets (RTS), a Ação Global dos Povos, Critical Mass, entre outros que buscaram, através da ressignificação de formas antigas de manifestações, como passeatas e comícios, trazer à cena pública internacional um protesto em forma de carnaval de rua. Segundo relatos dos membros e organizadores desses movimentos, sua essência estava na "[...] valorização da autonomia e espontaneidade dos participantes" (Freire Filho; Cabral, 2008, p. 175-181). De acordo com os estudos sobre esses movimen- 
tos, muitos buscavam se apropriar de formas culturais simbolicamente instituídas e subvertê-las, como no caso dos carnavais ou festivais oficiais, que possuem suas regras e datas estabelecidas pelas autoridades, mas que, nas manifestações do RTS, se transformavam em "protestival", movimentos diferenciados e caóticos, como afirmam Freire Filho e Cabral (2008, p.180), ao relatar a fala de um dos membros do RTS:

[...] enquanto os festivais oficiais são organizados dentro de preceituadas linhas retas e retangulares, as festas do RTS são vórtice que envolve as centenas e milhares de participantes (homens, mulheres, jovens e crianças) num estado "incontrolável de caos criativo”, capaz de romper com a “obsessão cultural pela linearidade, ordem e regularidade, evidenciada pelas estradas e pelos carros”.

Outras características que marcaram profundamente esses movimentos foram a larga utilização de ações performáticas nas manifestações, a ocupação dos espaços públicos e o uso das novas mídias e redes de relacionamento sociais para divulgação e publicização das imagens das manifestações e ocupações. As novas tecnologias de informação e comunicação, atreladas às novas mídias e às redes sociais virtuais, passaram a ser utilizadas como mecanismos de aglutinação e convocação dos participantes, estabelecendo um caráter diferenciado dos movimentos sociais anteriores e formando um coletivo em rede, conectado no ciberespaço, heterogêneo e múltiplo, como afirmam Ortellado e Ryoki (2004, p. 17), pesquisadores que estudaram o movimento Resistência Global no Brasil:

Uma das características mais distintivas do nosso movimento, em oposição àquele dos anos de 1960 e 1970, é a forma de organização por redes. [...] Redes não são organismos com uma estrutura organizacional definida ou com posições uniformes - elas são flexíveis, fluidas, plurais e descentralizadas. Redes são uma forma relativamente nova de associação, na qual as "partes" (que podem ser indivíduos, organizações ou mesmo outras redes) se unem para perseguir objetivos específicos, respeitando apenas princípios gerais acordados.
Além disso, Ortellado e Ryoki (2004) identificaram que o movimento da Resistência Global no Brasil inspirou-se nos acontecimentos de 1999, com os protestos antiglobalização realizados em Seattle. Segundo os autores, o grupo buscou uma forma de mobilização ampla e autônoma para os protestos contra o FMI e o Banco Mundial em 2000 na cidade de São Paulo, excluindo a participação dos partidos políticos:

Foi mais ou menos com a imagem de Seattle em mente que buscamos construir uma mobilização ampla e autônoma para os protestos contra o FMI e o Banco Mundial em São Paulo no dia 26 de setembro (S26). Fizemos um esforço grande para mobilizar movimentos sociais amplos, mas procuramos restringir a participação dos partidos políticos que têm um amplo e unívoco histórico de aparelhamento dos movimentos. Com o passar do tempo, no entanto, ficou claro que nosso movimento seria formado, sobretudo, por ativistas de grupos contraculturais e socialistas libertários, dos movimentos estudantil independente e ecologista radical e da parte jovem e radical dos movimentos feminista e gay. A partir desse núcleo de ativistas que participaram da organização, mobilizávamos um contingente fluido de jovens de diferentes grupos e pontos da cidade (Ortellado e Ryoki, 2004, p. 11).

Outro meio muito utilizado por grupos e movimentos sociais foram os blogs e sítios, ou seja, locais de espaço disponível na Internet que permitissem a publicação de artigos, opiniões, agendas e informações sobre ações e manifestações públicas. Em geral, buscavam uma autonomia em relação às instituições políticas tradicionais, como partidos políticos e sindicatos. Alguns desses blogs apresentavam discursos de repulsa ao sistema político como um todo, como é o caso do Blog Provos.Brasil (s/d), que adverte todos aqueles que o acessam: "Aviso: as pessoas que alimentam esse Blog são apolíticas. Não acreditamos em políticos brasileiros e muito menos nos partidos políticos. Logo, não defendemos nenhum deles exceto sua destruição".

O caráter aparentemente anárquico desses movimentos corresponde à descrença quanto ao sistema político da democracia re- 
presentativa e seus atores tradicionais, o que levou a uma ausência de lideranças políticas. Muitos desses grupos se colocam como um conjunto de indivíduos e grupos de indivíduos que buscavam compartilhar um espaço comum, sem haver uma plataforma política definida por lideranças. Como apontam Ortellado e Ryoki (2004, p. 19):

\begin{abstract}
Não se tratava de uma rede de grupos que tinham posições definidas e se coordenavam, mas de um espaço onde grupos e indivíduos coabitavam de forma sobreposta e entrecruzada. Isso, na verdade, expressava uma tendência mais ampla dos próprios grupos de se estruturarem cada vez mais como redes e se tornarem eles também cada vez mais fluidos e indefinidos. Isso trazia, tanto para o âmbito da rede quanto para o âmbito dos grupos, novos desafios e questões.
\end{abstract}

Pierre Lévy (2011) argumenta que a forma de estruturação dos movimentos sociais em rede no ciberespaço assume um aspecto particular quanto ao conteúdo e quanto à forma. Não há a rigidez de uma causa única e a necessidade da fixidez de uma identidade política e cultural dos grupos. Para o autor, as relações dos grupos no ciberespaço são autônomas em um movimento contínuo e heterogêneo.

Está claro, o movimento social e cultural que o ciberespaço propaga, um movimento potente e cada vez mais vigoroso, não converge sobre um conteúdo particular, mas sobre uma forma de comunicação não midiática, interativa, comunitária, transversal, rizomática. Nem a interconexão generalizada, nem o apetite das comunidades virtuais, nem tampouco a exaltação da inteligência coletiva constituem os elementos de um programa político ou cultural no sentido clássico do termo. E ainda assim, todos os três talvez secretamente movidos por dois "valores" essenciais: a autonomia e a abertura para alteridade (Lévy, 2011, p. 134).

Essa característica de autonomia e sentimento de alteridade engendra um movimento de autoexpressão individual, originando os boicotes individuais. Indivíduos isoladamente iniciavam um movimento de boicote a determinado produto, marca, empresa, programa de tevê, jornal, celebridade etc. As ações inde- pendiam de organização ou discussão prévia sobre o tema; bastava alguém postar nas redes sociais virtuais um manifesto de repulsa ou denúncia sobre determinado fato, que imediatamente vários outros indivíduos aderiam ao boicote manifestando-se a favor da causa. Desse modo, imagens fotográficas, vídeos, frases, depoimentos, abaixo-assinados, entre outros, passaram a circular no ciberespaço, deslocando o sentido e o lugar do enunciado político, provocando manifestações e mobilizações diversas, em uma velocidade até então não experimentada pela sociedade. Tal processo trouxe à cena um tipo de ativista sem causa especifica determinada, mas com uma forma de identificação com os problemas apresentados pelos outros, fomentando um processo de alteridade e solidariedade. Se, por um lado, esse momento demonstrou ser um processo de individualização ${ }^{9}$ e narcisismo consumista, por outro lado e dialeticamente, fomentou-se uma interconexão maior entre os indivíduos em escala global, ocasionando um sentimento de solidariedade mútua.

Desse modo, o que se busca destacar é o tipo de ação que o ciberespaço proporcionou aos indivíduos, tenham eles ideais de esquerda ou conservadores. A fala do sujeito enunciador e o lugar do enunciado deslocaram-se, provocando mudanças significativas. O lugar ocupado pelo enunciado - político, intelectual, ambientalista ou econômico -, com o advento do ciberespaço e com a cibercultura, passou a ser tensionado por sujeitos heterogêneos e múltiplos, dissonantes e multifacetados, portadores de mecanismos de mobilização também múltiplos, proporcionados pelas novas tecnologias de informação e comunicação. Assim sendo, uma manifestação pode ser acionada por um celular a qualquer momento, em qualquer lugar, por qualquer motivo. O deslocamento do lugar do enunciado subverte os lugares hegemônicos da fala (grande mídia televisiva, jornais, sindicatos, partidos políticos etc.), e ${ }^{9}$ Zygmunt Bauman (2009) apresenta uma significativa análise do que ele denomina de sociedade individualizada. 
o surgimento de outro ator que enuncia, traz à cena o ciberativista que ressignifica uso das imagens e das informações, subvertendo pautas e impondo agendas.

Apesar das estruturas fluídas, autônomas e multiformes que o ciberespaço e a cibercultura constituíram, elas fizeram teóricos, como Zygmunt Bauman (1999; 2009), apresentarem uma crítica cética quanto aos indivíduos globalizados em uma sociedade voltada unicamente para o consumo. Presenciamos, nesta década, com o agravamento da crise econômica e financeira em 2008, o surgimento de inúmeras manifestações e mobilizações sociais voltadas para causas radicalmente democráticas. São causas politicamente contra-hegemônicas, que propõem novas agendas políticas, éticas e morais, exigindo novos rumos e formas para a democracia e para as políticas econômicas e sociais. Tais movimentos e manifestações foram mobilizados por um contingente majoritariamente jovem, como no caso dos movimentos Occupy, nos Estados Unidos, dos Indignados, na Espanha, o movimento estudantil no Chile, e a grande mobilização dos jovens na Praça Tahrir, no Egito, que ficou conhecida como Primavera Árabe, além de inúmeros outros movimentos em várias regiões do mundo. Apesar das diferenças e especificidades históricas e políticas de todos esses movimentos, o que se pode dizer é que a presença dos jovens, a radicalidade das propostas e os meios e formas de mobilização apresentaram um conjunto de similitudes, o que já pôde ser visto nas primeiras manifestações contra a globalização no início da década de 1990, mas que tomou outras proporções e magnitudes com o agravamento da crise econômica mundial.

Nesses últimos dois anos, os movimentos e manifestações sociais contra o modelo econômico dos países centrais se acentuaram e tomaram novas direções. Além do que já havíamos presenciado na década de 1990, com as grandes manifestações de rua, dos carnavais, protestos, além do enfrentamento dos jovens com as autoridades policiais, os novos movi- mentos e manifestações sociais partiram para uma tática ocupacional do espaço público. Tais espaços são carregados de significados, como é o caso da ocupação de Wall Street, Nova York, em 2011, que, simbolicamente, representa o centro do capital financeiro mundial. Tal movimento de ocupação apontava para uma mudança no conteúdo dos movimentos sociais que ali atuavam. Diferentemente do que ocorreu na década de 1980, como foi demonstrado por Castells (2001b), esses novos movimentos não se fragmentam em lutas isoladas por identidades, etnias, de gênero etc. Eles lutam por uma causa comum, ou seja, contra o modelo econômico capitalista financeiro e contra a forma de democracia representativa. Seja nos EUA, seja nos países europeus, seja na América Latina, a insatisfação contra um sistema político e econômico foi a tônica desses novos movimentos, e a ocupação de praças, avenidas, prédios e espaços públicos carregados de significados foi a expressão da indignação crítica ao modelo hegemônico ideologicamente liberal, que centralizou grande parte das discussões políticas, sociais e econômicas das últimas quatro décadas.

Segundo Maria da Gloria Gohn (2012), esses novos movimentos sociais de ocupação passaram a transformar o enunciado das manifestações sociais, trazendo, para esfera pública, "problemas da vida cotidiana" que, devido ao caráter hegemônico do capitalismo financeiro globalizado, atingem invariavelmente todos os indivíduos no mundo. Ou seja, desemprego, salários, educação, serviços sociais, saúde, moradia etc. deixaram de ser problemas particulares das sociedades periféricas, pois atingem, em maior ou menor grau, todas as sociedades.

Eles (os movimentos) estão repolitizando as demandas socioeconômicas e políticas, independentemente de estruturas partidárias, tendo como um dos focos a oposição ao mercado financeiro, especialmente ao capital especulativo que atua em escala global e as grandes corporações financeiras.

Passaram da crítica à globalização (ou al- 
terglobalização) para a negação da globalização e seus efeitos sobre a economia e o social, especialmente após a crise econômico-financeira de 2008 (Gohn, 2012, p. 24).

Outro ponto importante nesses novos movimentos e grupos sociais é o consenso em torno do discurso de insatisfação quanto às estruturas econômicas e políticas tradicionais que organizam a sociedade contemporânea. Esses novos atores sociais utilizam seus sites, blogs e redes sociais para divulgar outro discurso e outra possibilidade de viver no mundo, outra maneira de experimentar a democracia. E, nesse sentido, o blog do movimento @ocupadopovos, ${ }^{10}$ em seu manifesto, é um claro exemplo:

Somos pessoas normais, pessoas como você, trabalhador@s, estudantes, desempregad@s, aposentad@s; vivemos no Brasil ou em outros países e independente da nossa situação, estamos unidos por um pensamento comum: mudar o sentido que a nossa sociedade está tomando, lutar contra a degradação da nossa condição de vida.

Somos uma organização social que não está vinculada a nenhum partido político, sindicato ou empresa; somos um grupo livre e independente, formado por pessoas correntes, que unem forças por um objetivo comum, uma democracia real e participativa, onde a sociedade é a prioridade, e não os mercados ou governos.

Por alguns somos considerados progressistas, por outros conservadores, muitos com ideologias bem definidas e tantos outros que se consideram apolíticos, mas todos estamos preocupados e indignados com o panorama político, econômico e social que vemos ao nosso redor. Pela corrupção da classe governante, pela ganância das empresas, pela falta de ética dos bancos e pela indefesa do cidadão que vai a pé e sozinho.

Chegou a hora de combater tanta injustiça, tanto desequilíbrio, e a única forma de conseguirmos é através da união entre toda a sociedade, não para lutar por um partido ou um político, mas sim por mudanças reais do atual sistema econômico e político.

Precisamos de união, precisamos deixar as bandeiras, precisamos deixar de pensar que a política tem de ser representada, podemos decidir por nós mesmos.

${ }^{10}$ Esse movimento faz parte do movimento social Os Indignados da Espanha que, a partir de 2011, se espalhou por vários países, dentre eles o Brasil.
As prioridades de qualquer sociedade avançada têm de ser a igualdade, o progresso, a solidariedade, o acesso livre à cultura e educação, à sustentabilidade ecológica, ao bem-estar.

Existem direitos básicos que deveriam estar cobertos nestas sociedades: direito à moradia, ao trabalho, à cultura, à saúde, à educação, à participação política, ao livre desenvolvimento pessoal.

$\mathrm{O}$ atual funcionamento do nosso sistema econômico e político (sistema representativo) não atende a estas prioridades sociais e é um obstáculo para o progresso da humanidade.

A democracia parte do povo (demo=povo; cracia=governo); assim é que o governo deve ser, do povo. Por outro lado, neste país, a maior parte da classe política sequer nos escuta. As suas funções deveriam ser de levar a nossa voz às instituições, facilitando a participação política cidadã mediante canais diretos, procurando o maior benefício para o grosso da sociedade; mas o que eles fazem é enriquecer às nossas custas, atendendo tão somente aos grandes poderes econômicos; lutam apenas pelo poder, como uma disputa pessoal entre eles mesmos, e nos impõem uma ditadura política partidária, que é encabeçada pelos mesmos políticos de sempre.

A ganância e a acumulação de poder nas mãos de poucos geram desigualdade e injustiça, a qual conduz à violência, algo que não aceitamos. O obsoleto e insustentável modelo econômico vigente bloqueia a máquina social em uma espiral que consome a si mesma, enriquecendo poucos e afogando na pobreza e na escassez a maioria da população, até que, por fim, tudo isso se colapse e, outra vez, sejamos nós os prejudicados.

A vontade e o propósito desse sistema é a acumulação de dinheiro, prioridade por cima da eficácia e bem-estar social. Mal gastando recursos, consumindo o planeta a uma velocidade insustentável.

Os cidadãos formam parte da engrenagem de uma máquina destinada a enriquecer uma minoria que não sabe e não quer saber das nossas necessidades; tudo que pode ser comercializado e mercantilizado será; a educação, a saúde e a cultura já estão à venda e tantos outros direitos seguem o mesmo caminho. Somos anônimos, mas sem nós nada disso seria possível, porque somos nós que movemos o mundo. Como sociedade, aprendemos a não confiar o nosso futuro a uma abstrata rentabilidade econômica que nunca termina em benefício da maioria; juntos, podemos eliminar as carências que todos sofremos. É necessária uma revolução ética, não podemos permitir que sigam colocando o dinheiro por cima do ser humano. Por tudo isso, estou indignado. 
Acredito que posso mudá-lo.

Sei que, unidos, podemos.

Sai com a gente, é o seu direito.

Entenda a diferença entre a política representativa (atual sistema político) e política participativa (sistema político que queremos).

(Manifesto - Democracia Real Brasil, s/d)

No âmbito das práticas e ações de mobilização dos indivíduos, esses novos movimentos sociais, tendo as redes sociais virtuais como instrumento, fizeram do ciberespaço o meio por excelência para a divulgação, principalmente com o uso de imagens, dos atos de manifestação e ocupação de espaços públicos como também o principal meio de mobilização e organização das manifestações e ocupações. As novas mídias, as redes sociais virtuais, os serviços de $\mathrm{SMS}^{11}$ e similares foram ressignificados pela causa por esses novos atores e movimentos sociais. Ter um perfil no Facebook, no Twitter, ou um smartphone com serviços de Internet passou a representar mais do que um entretenimento para um indivíduo isolado em um mundo voltado para o consumo (Bauman, 2009), mas uma ferramenta útil e ágil para organizar, divulgar imagens e mobilizar um protesto ou uma ocupação.

Twitter, Facebook, YouTube, Linkedin, Groupon, Zynga etc. são acionados principalmente via aparelhos móveis, como Blackberries, iPhones etc. Ferramentas do ciberativismo se incorporaram ao perfil do ativista. Saber se comunicar on-line ganhou status de ferramenta principal para a articulação as ações coletivas (Gohn, 2012, p. 24).

Além da grande utilização dos meios e ferramentas do ciberespaço, esses movimentos e grupos sociais buscam divulgar ao máximo suas ações e, para isso, a utilização da imagem passou a ser estrategicamente fundamental. Documentar e transmitir on line as ações e manifestações nos espaços públicos foram a forma encontrada para mobilizar ainda mais um número cada vez maior de ativistas. No entanto, preocupados em enfrentar o sistema,

${ }^{11}$ Short Message Service (Serviço de mensagens curtas) são mensagens enviadas entre aparelhos telefônicos por meio de rede de telefonia móvel. em construir a contra-hegemonia, ao propor um novo lugar de discurso, de denúncia e de divulgação das lutas através de imagens no ciberespaço, esses movimentos se vêm obrigados também a enfrentar os efeitos negativos do uso da tecnologia. Se uma boa parte da organização e da divulgação do movimento é, agora, mediado pelo mundo virtual, os obstáculos ligados à virtualização das relações sociais passam a ser um problema também central para a eficácia desses movimentos e manifestações. Ou seja, até que ponto a virtualização e a divulgação de imagens no ciberespaço criou um espaço realmente alternativo para a luta desses movimentos e manifestações sociais? Qual o risco da espetacularização e banalização que o uso excessivo das imagens no ciberespaço pode trazer às lutas contra-hegemônicas? E, por fim, em que acepção o uso e o sentido das imagens podem deslocar o espaço hegemônico do consenso da grande mídia, permitindo outras interpretações e discursos?

\section{ESPETACULARIZAÇÃO E ENGAJA- MENTO: dilemas no uso da imagem}

É perceptível que a expansão da internet como meio de comunicação e, em particular, a proliferação das redes sociais são mais água no moinho da espetacularização das relações. A “cultura da virtualidade real", como chamou Castells (2001a, p. 459), se constitui em um espaço de articulação do simbólico. O meio virtual permite que essa articulação seja realizada com uma maior autonomia frente à dinâmica do ser, ou seja, como um meio homogêneo de representações, o meio virtual não exige que as representações prestem referência constante ao real. Como exemplo, podemos pensar na construção da identidade pessoal nesse meio. As características reivindicadas não precisam se articular, de imediato com as características reais da pessoa - há um espaço de manobra que está ligado ao distanciamento temporal e espacial do mundo virtual em relação ao meio 
presencial. No meio virtual, portanto, a produção da imagem se torna tarefa ordinária no estabelecimento das relações sociais.

Na teoria de Guy Debord (2008), a imagem tem papel central no caráter conservador da espetacularização. Por mediar as relações entre as pessoas de forma a inverter a sequência ontológica entre o ser e o parecer, o espetáculo é, em si, alienante.

As imagens que se destacaram de cada aspecto da vida fundem-se num fluxo comum, no qual a unidade dessa mesma vida já não pode ser restabelecida A realidade considerada parcialmente apresenta-se em sua própria unidade geral como um pseudomundo à parte, objeto de mera contemplação. A especialização das imagens do mundo se realiza no mundo da imagem autonomizada, no qual o mentiroso mentiu para si mesmo. O espetáculo em geral, como inversão concreta da vida, é o movimento autônomo do não vivo (Debord, 2008, p. 13).

Debord (2008) segue os traços gerais da visão de Adorno e Horkheimer (1995) sobre a indústria cultural. Para eles, a reificação da cultura, que seria advinda de sua mercantilização, torna-se empecilho para o real desenvolvimento humano. Essa proximidade teórica explica a sensação pessimista que temos ao ler tantos os escritos de Debord ou de Adorno e Horkheimer sobre a dinâmica da cultura no capitalismo. Não parece haver caminho, dentro dessa dinâخ mica, para lutas e disputas de significados.

A positivação das imagens atinge uma proporção extrema na vida social com as redes sociais virtuais. Se, de um lado, agora todos produzem imagens, cada vez mais as nossas particularidades são conectadas dentro de um $\dot{2}$ ambiente de indiferenças (como afirmou Ador. no, ambiente das trocas injustas e da cultura - indiferenciada). As manifestações tinham sua sociabilidade dentro de uma estrutura, como já tratamos no item anterior. A imagem não precisava dizer nada além do que expor as bandeiras e os apoios que tais bandeiras têm. De um lado, os manifestantes tinham pouco poder na produção da imagem, podiam apenas oferecer possibilidades para as imagens que entrariam no circuito da mídia; de outro, o apelo ao apoio se dava em relações não dominadas pelas imagens, mas sim nas estruturas organizativas, como sindicatos, partidos, movimentos. As imagens, nas manifestações atuais, passam a ter importância central: são formas de comunicação produzidas pelos próprios sujeitos; e, ao mesmo tempo, jogam a especificidade de certa luta no mar indiferenciado da sociedade do espetáculo.

No âmbito político, surge, então, um problema crucial. Como intervir na forma de organização da sociedade, influenciar posições de maneira crítica ao status quo, num meio que pasteuriza as posições, aplica um denominador comum a todas as visões sobre organização social (onde comunismo e anarquismo se parecem mais com modismos e menos com posicionamentos radicais)? A solução está em romper com a "regularidade ou normalidade" cotidiana, o que para Wilson Gomes (2004, p. 307), “... é [...] a concatenação de eventos e objetos da realidade em conformidade com as expectativas habituais". No cotidiano, “[...] ainda que a percepção da homogeneidade dos ritmos e relações do real seja fundamental para que os seres humanos normais organizem suas ações, a regularidade como que arrefece a curiosidade, enfraquece a atenção, dispensa a memória”.

A política exige persistência no tempo, pois a duração temporal dos vínculos tem relação com a possibilidade de alterações mais profundas da organização social. Nesse sentido, os manifestantes, ao produzirem e divulgarem as imagens de suas manifestações políticas, estão dentro de uma tensão inerente à sociedade do espetáculo, que se dá entre a singularização do evento e o desgaste de sua imagem. Como, há tempos, afirmou Susan Sontag (2004, p. 196):

Consumimos imagens num ritmo sempre mais rápido e, assim como Balzac suspeitava que as câmeras exauriam camadas do corpo, as imagens consomem a realidade. As câmeras são o antídoto e a doença, um meio de apropriar-se da realidade e um meio de torná-la obsoleta.

Torna-se fundamental a estratégia do 
choque, para usar um termo de Walter Benjamin (2012). O choque seria um desdobramento da sensibilidade moderna, da forma necessariamente distraída em que vivemos, dado o excesso de estímulos que sofremos no cotidiano moderno. O choque é a forma de abertura essa busca:

[...] a atenção e a memória são acionadas diante de fatos e fenômenos que frustrem as expectativas, introduzindo um ritmo inesperado ou uma conexão não habitual. Nesse caso, o organismo como que desliga o piloto automático e reassume o comando, diante do sobressalto criado pela constatação de que alguma coisa está fora da ordem, alguma coisa supera a medida, alguma regra foi burlada. De forma que, se for possível introduzir, por artifício, uma alteração no horizonte de expectativas, se for possível provocar uma ruptura na regularidade, então será possível capturar, por arte, a atenção e a memória (Gomes, 2004, p. 307).

No entanto, apenas o choque não garante a crítica social e política. Tudo pode acontecer como ocorre no cinema hollywoodiano ou no mundo da publicidade. Choques seguidos de apaziguamento, uma lógica da insegurança ou segurança que busca uma variação sentimental, que gera divertimento e tem como produto final o alívio. A luta por mudanças para a atenção. Na luta política. há também

sociais radicais deve enfrentar esse modelo; deve, a partir do choque, criar um incômodo de difícil dispersão.

Parece-nos que a experiência das novas tecnologias de informação e comunicação no ciberespaço e das redes sociais virtuais tem sido vivida com certa consciência dos obstáculos à efetivação de reivindicações por parte dos movimentos sociais. De forma que é possível perceber, em sua produção imagética, tentativas de enfrentamento e superação dessa tensão. Vejamos dois casos que ilustram o dilema presente hoje para os movimentos e manifestações sociais.

Os cartazes se referem a uma música que tem feito muito sucesso no Brasil "Tchu Tcha Tcha". Na letra, diz-se que se quer "Tchu", se quer "Tcha”. A força do cartaz está em rejeitar o que a música propõe (como uma clara crítica ao caráter banal da música) e afirmar uma reivindicação considerada mais importante. Ainda que haja, na produção do cartaz, uma crítica à alienação (ou seja, ao tipo de música da indústria cultural), o que nos interessa aqui é outra perspectiva. Por ser um diálogo com um produto de consumo de massas, esse cartaz é reproduzido com o mesmo impulso que o próprio produto. Mas sua ressignificação e sua
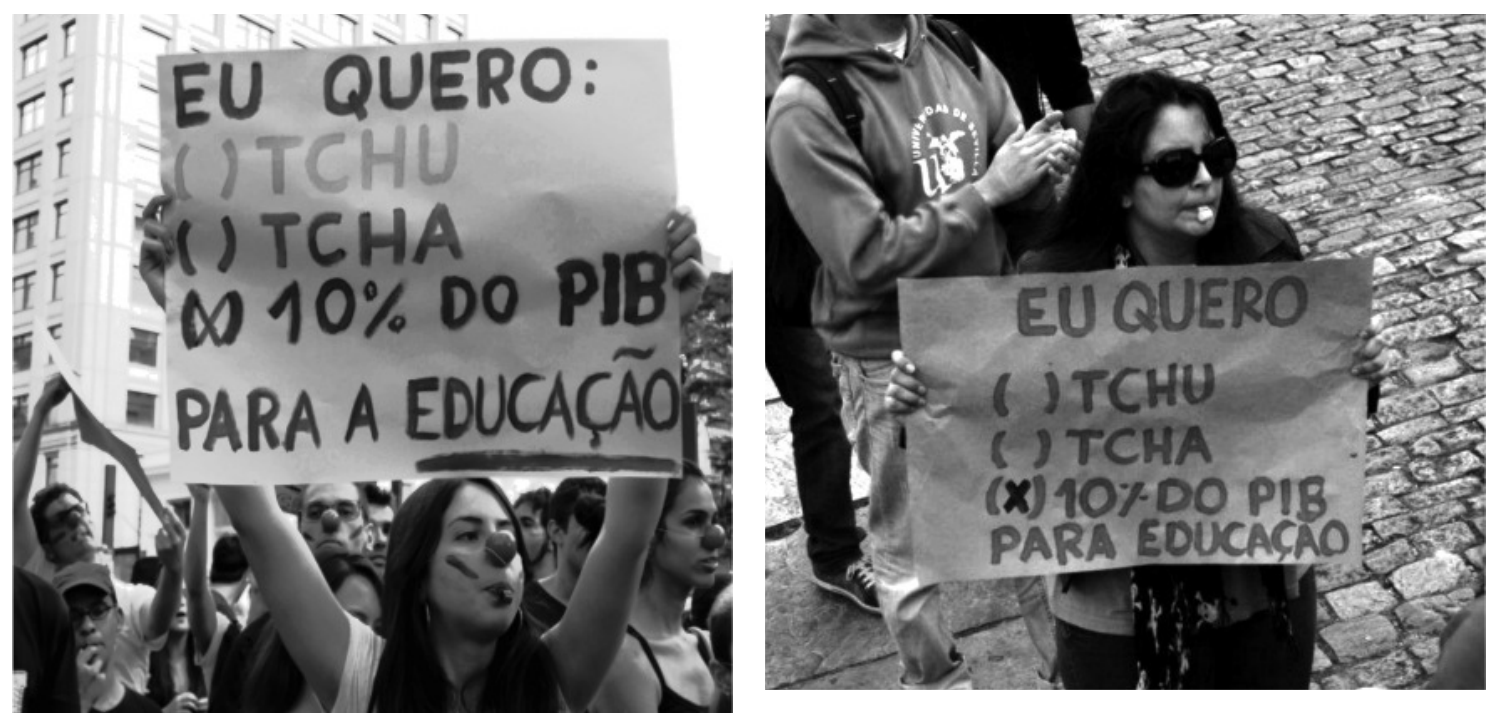

Daia Oliver/R7

Foto veiculada no blog UFOP em luta, sem créditos: http://ufopemluta.wordpress.com/fotos-e-videos/\#jp-carousel-104 
desterritorialização permitem tal reprodução. O efeito é que as imagens produzidas são facilmente confundidas; não sabemos mais ao certo onde vimos tal cartaz, sobre o que era, e quais os desdobramentos daquela manifestação. Nessas fotos, busca-se principalmente reproduzir a própria manifestação, transferindo para o meio virtual a exposição das reivindicações, o que ocorreu primeiro nas ruas. Como reprodução, essas fotos se preocupam em deixar à vista, como pano de fundo, a rua e os manifestantes, de forma a nos transmitir a ideia de que estamos vendo exatamente o que aconteceu.

No entanto, a imagem, na sociedade do espetáculo, não só produz desgaste. Cremos que a novidade das redes sociais virtuais - que permitem a circulação da produção de mídias pelos próprios manifestantes - impede uma aplicação plena da perspectiva de Debord ao caráter conservador da espetacularização. Se o espetáculo é uma relação social mediada por imagens, talvez caiba pensarmos também se relações sociais diferentes mediadas por imagens terão o mesmo caráter conservador. $\mathrm{Ou}$ seja, com a produção das imagens não só pelas grandes empresas de mídia, não podemos pensar numa mudança na caracterização política do espetáculo? Sem identificar essa possibilidade, estamos fadados a sobrepor os aspectos da tecnologia à política.

Outro exemplo mostra uma estratégia mais instigante, que permite que pensemos a questão da espetacularização com mais abertura.

A primeira imagem se reporta à luta pela

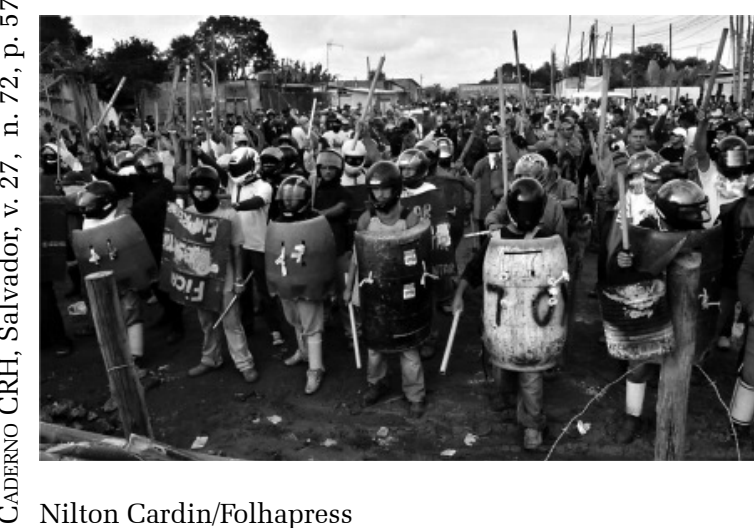

manutenção de uma ocupação urbana (conhecida como Pinheirinho), na região metropolitana de São Paulo, ameaçada com um mandato de reintegração de posse. De um lado, a imagem capta a disposição real de luta desses moradores em enfrentar o anunciado despejo. Apesar do acento quixotesco, esses moradores empunham armas reais (paus, capacetes, escudos improvisados) e parecem dispostos a enfrentar fisicamente a polícia. No entanto, sua força política está na composição imagética. Ao apresentar um moderno exército de Brancaleone, eles afirmam, em vez da força física de suas armas, sua fraqueza, a desigualdade entre os moradores e os aparatos policiais. Uma caricatura que busca constranger o uso da força policial. Sua tática é criar uma imagem que considera a relação espetacular; no entanto, é feita de forma a ironizar o uso da imagem como maneira de assustar o oponente, de supervalorizar sua força. Pelo humor, esses moradores criaram uma imagem que humaniza sua luta. E, por outro lado, a divulgação dessa imagem nas redes sociais virtuais buscava denunciar uma estrutura de opressão por parte do Estado.

A segunda se refere às manifestações pela educação pública no Chile. Os estudantes, buscando a atenção midiática, se travestiram de super-heróis. Diferentemente da primeira, não há nenhum efeito relativo ao enfrentamento físico ao se vestir de super-heróis. Sua intenção está totalmente na produção da imagem. Há, como na foto anterior, uma re-

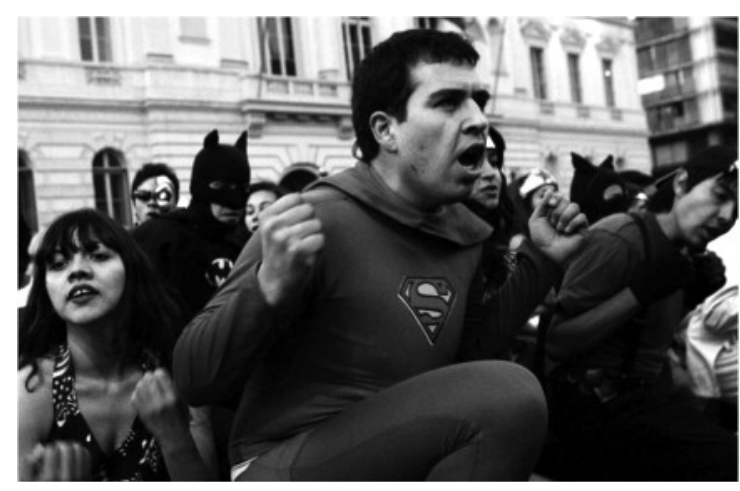

Victor Ruiz Caballero/Reuters 
presentação quixotesca. Afirma-se, ao fornecer uma representação a crença na força da mobilização, apesar da aparente fraqueza. Ou seja, busca-se confrontar a força do governo, do status quo, com os superpoderes da mobilização e da conquista da opinião pública.

No que tange à produção da imagem, vemos um caminho interessante da luta contra -hegemônica dentro dessa sociedade espetacular: a imagem autorreflexiva, irônica. A ironia se realiza quando se estabelece uma diferença entre o dito e o que se quer dizer de fato. Frente a uma ironia, somos, por um momento, acompanhados em nossa esperança e, repentinamente, abandonados. A imagem do protesto, como forma de demonstração de força e grandeza, é o percurso básico, o que esperamos ao olhar para a imagem. No entanto, sofremos uma reviravolta quando se demonstra a força de maneira patética, seja se apegando a uma superforça ou a um evidente improviso.

Com esse processo, a produção da imagem é tematizada e, também, a própria espetacularização. Tenta-se não apenas chamar a atenção, mas destacar o fato de sua apreensão imediata. O que essas imagens parecem nos dizer é que, se a mercantilização da vida e a consequente espetacularização das relações sociais a têm banalizado, pasteurizando as representações, uma forma de enfrentar a banalização não é negar a forma espetacular, mas, de certa maneira, levá-la ao absurdo. O retrato dessa luta, numa estética realista, parece presa fácil do circuito desgastado das representações espetacularizadas - a imagem não se destacará das infinitas representações disponíveis nas redes sociais virtuais. A ironia particular à própria espetacularização parece ser um instrumento interessante, ao permitir um destaque (através da manipulação de representações), mas, ainda assim, não é feita sem oferecer um contato com o real - não se vestiram de super-heróis apenas para chamar à atenção, mas para revelar, reflexivamente, o jogo de forças desigual.

Esse período de intensificação dos usos das imagens não nos parece significar simples- mente o sufocamento das lutas sociais pela virtualização e espetacularização da vida. Ele deve ser lido, sobretudo, como uma virtualização das lutas sociais, o que desencadeia uma guerra de imagens. Nesse sentido, a cultura de contra-hegemonia, hoje, está se configurando também como uma cultura de imagens contra -hegemônicas. Antes de condenarmos a guerra virtual das imagens por ser feita num campo da espetacularização, temos de buscar entender, analisar a produção das imagens, que está sendo guiada pela intenção do subalterno, como se apresentam, quais suas opções estéticas, como se produzem.

Se considerarmos que essas imagens estão sendo produzidas num novo momento organizativo, outro aspecto se torna relevante. O deslocamento da enunciação, com o descrédito dos locais institucionalizados, abre campo para discursos que não encontram finalidade clara, ganhando um caráter predominantemente negativo. Na produção da imagem, essa abertura pode se distanciar ainda mais do caráter publicitário, espetacularizado. As imagens produzidas pelos movimentos recentes, com novas formas organizativas, estão numa posição privilegiada no desenvolvimento de imagens provocativas, incômodas, que não se obrigam a indicar conclusão, solução imediata (ou alívio) a esse incômodo, como uma ideologia socialista, por exemplo. ${ }^{12} \mathrm{O}$ momento crítico às organizações institucionalizadas pode significar também um desenvolvimento intenso de imagens abertas, que lutam contra a espetacularização, cujo foco é a abertura, o incômodo que não precisa achar alívio imediato.

${ }^{12}$ Aqui se pode pensar nas dificuldades que as organizações institucionalizadas têm em ganhar legitimidade hoje, com produção da imagem, já que a produção de imagens orientada por um fim claro, de causar específica identificação e engajamento em certo projeto, tem sofrido desgaste, tanto por um desgaste geral das instituições quanto por um desprestígio de qualquer forma clássica, publicitária. 


\section{CONCLUSÃO}

O fundamento de toda atividade crítica, portanto, deve se basear na capacidade de descobrir a distinção e as diferenças por baixo de toda superficialidade e aparentemente uniformidade e semelhança (Gramsci, 2007b, v. 6, p. 69).

Muito se teorizou sobre a subjetividade política dos jovens dos anos de 1990, de seu comportamento apolítico e alienado frente às grandes causas sociais. Muito se escreveu sobre a impossibilidade de um modelo político e econômico capaz de suplantar e substituir o binômio capitalismo globalizado e democracia representativa. Muitos deixaram de acreditar na radicalidade da ação social, nos movimentos sociais e na possibilidade da utopia socialista. Muitos acreditaram no fim da história; na individualização acentuada dos indivíduos atônitos e passivos, navegando sozinhos nas redes da Internet; no consumismo desenfreado como marca identitária na sociedade do século XXI. Muitos movimentos e partidos de esquerda aceitaram o jogo da governabilidade e do governo de coalizão, da primazia do mercado global e da enunciação hegemônica de que o t capitalismo global e financeiro, juntamente స com a democracia representativa, seriam as ฮ̊ únicas soluções para as crises mundiais, sejam elas políticas, econômicas ou sociais. No i entanto, o que passamos a presenciar e a experimentar na última década, principalmente nos últimos dois anos, foi a antítese de tudo i isso. Mesmo em seu caráter inacabado, incon$\dot{a}$ cluso e indeterminado, os novíssimos grupos స̃ e manifestações sociais de ocupação dos espaços públicos e simbólicos trouxeram uma nova perspectiva política e social; trouxeram de volta o sentimento de indignação e de insatisfação quanto ao status quo econômico da globalização financeira e seu modelo de democracia. Mostraram que é possível ressignificar os instrumentos midiáticos de controle e de produção do discurso hegemônico, assim como também é possível fazer uso da imagem como forma de divulgar outro discurso, outro enunciado, outra forma de fazer política contra-hegemônica, demonstrando ser possível exercer uma atividade crítica, romper com superficialidades dos discursos, propor, pautar e exigir outras demandas, ou outros sentidos para a vida em sociedade, mesmo que utópicos.

Reconhecemos a importância da crítica que os teóricos contemporâneos, como o filósofo Slavoj Zizek (2012), têm feito aos movimentos e manifestações sociais nos últimos dois anos, chamando a atenção para o que será feito no dia seguinte; para o perigo que os manifestantes e ativistas, principalmente os jovens, sofrem de se apaixonarem por si mesmos e de viverem apenas a experiência da ocupação e da manifestação como mais um evento entre tantos outros que o mundo atual pode oferecer; para a falta de planos programáticos e de uma teoria clara de como tomar o poder; e para o apreço aos sonhos utópicos de um socialismo libertário etc. Acreditamos que, com este trabalho, indicamos que pode existir algo "para além das esperanças perdidas". Buscamos identificar como as novas gerações vêm apresentando formas inovadoras de contestar o poder hegemônico e de que é possível pensar diferente. E que a democracia radical se constrói, como coloca Jacques Rancière (2006), pelo dissenso, pela crítica e pela indignação. Se a pergunta é "o que será feito no dia seguinte?", nos parece certo que é para esses movimentos que a pergunta deve ser dirigida, pois a palavra está com eles.

Recebido para publicação em 24 de junho de 2013 Aceito em 09 de setembro de 2013

\section{REFERÊNCIAS}

ADORNO, Theodor W.; HORKHEIMER, Max. Dialética do esclarecimento. Rio de Janeiro: Jorge Zahar. 1995.

BAUMAN, Zygmunt. Globalização: as consequências humanas. Rio de Janeiro: Jorge Zahar, 1999. 
Capitalismo parasitário. Rio de Janeiro: Editora Jorge Zahar, 2009.

A Sociedade individualizada: vidas contadas e histórias vividas. Rio de Janeiro: Editora Zahar, 2009.

BENJAMIN, Walter. A obra de arte na época de sua reprodutibilidade técnica. Porto Alegre: Zouk, 2012.

CANCLINI, Nestor Garcia. Diferentes, desiguais e desconectados. Rio de Janeiro: Editora da UFRJ, 2009.

CASTELLS, Manuel. A Sociedade em Rede. In: A era da informática: economia, sociedade e cultura. v. 1. São Paulo: Paz e Terra, 2001a.

. O poder da identidade. In: A era da informática: economia, sociedade e cultura. v. 2. São Paulo: Paz e Terra. 2001b.

COELHO, Alexandra Lucas. Tahrir: os dias da revolução no Egito. Rio de Janeiro: Editora Língua Geral, 2011.

COUTINHO, Carlos Nelson. Gramsci: um estudo sobre o pensamento político. Rio de Janeiro: Civilização Brasileira, 2007.

DEBORD, Guy. A sociedade do espetáculo. Rio de Janeiro: Contraponto, 2008.

FREIRE FILHO, João; CABRAL, Ana Julia Cury de Brito. Contra-hegemonia e resistência juvenil: Movimentos mundiais de contestação da ordem neoliberal. In: COUTINHO, Eduardo Granja (Org). Comunicação e contra-hegemonia. Rio de Janeiro: Editora da UFRJ, 2008.

GLADWELL, Malcolm. A revolução não será tuitada. Folha de São Paulo, 12 de dezembro de 2010.

GOHN, Maria da Gloria. Teoria dos movimentos sociais. São Paulo: Editora Loyola, 2007.

. A Revolução será tuitada. Revista Cult. n. 169. p. 23-27, 2012.

GOMES, Wilson. Transformações da política na área da comunicação de massa. São Paulo: Paulus, 2004.

GRAMSCI, Antonio. Cadernos do Cárcere: Os intelectuais. O princípio educativo. Jornalismo. v. 2. Rio de Janeiro: Civilização Brasileira, 2006.

- Cadernos do Cárcere: Maquiavel, notas sobre $\overline{\mathrm{o} \text { Estado e a política. Rio de Janeiro: Editora Civilização }}$ Brasileira, v. 3, 2007a.

Cadernos do Cárcere: Literatura. Folclore. Gramática. Rio de Janeiro: Editora Civilização Brasileira, v. $6,2007 \mathrm{~b}$.
LEMOS, André. Comunicação e práticas sociais no espaço urbano: as características dos Dispositivos Híbridos Móveis de Conexão Multirredes (DHMCM)”. Comunicação, mídia e consumo. v. 4, n.10, p. 23-40, 2007.

LÉVY, Pierre. Cibercultura. São Paulo: Editora, v. 34, 2011. MERRIFIELD, Andy. Crowd Politics. New Left Review. n.71, p. 103-115, 2011.

DÊNIS, Moraes de. Comunicação, hegemonia e contrahegemonia: a contribuição teórica de Gramsci. Porto Alegre, RS. Revista Debates, v. 4, n.1, p. 54-77, jan-jun. 2010.

OLIVEIRA, Francisco. Política numa era de indeterminação: opacidade e reencantamento. In: ; RIZEK, Cibele Saliba. A era da indeterminação. São Paulo: Boitempo, 2007.

ORTELLADO, Pablo; RYOKI, André. Estamos vencendo! resistência global no Brasil. São Paulo: Editora Conrad, 2004.

RANCIÈRE, Jacques. O dissenso. In: NOVAES, Adauto (Org). A crise da razão. Rio de Janeiro: Companhia das Letras, 2006.

SECCO, Lincoln. Gramsci e a revolução. São Paulo: Editora Alameda, 2006.

SONTAG, Susan. Sobre fotografia. São Paulo: Cia das Letras, 2004.

WARREN, Ilse Scherer. "Redes sociais e sociedade de informação". In: MAIA, Rousiley; CASTRO, Maria Ceres Pimenta Spínola (Org). Mídia, esfera pública e identidades coletivas. Belo Horizonte: Editora da UFMG, 2006.

ZIZEK, Slavoj. O Violento silêncio de um novo começo. In: Vários autores. Occupy: movimentos de protestos que tomaram as ruas. São Paulo: Boitempo. Carta Maior, 2012.

\section{Páginas na Internet}

Provos.Brasil [homepage na Internet], acesso em 30 de julho de 2012. http://provosbrasil.blogspot.com.br/

Manifesto - Democracia Real Brasil [homepage na Internet], acesso em 30 de julho de 2012. http:// democraciarealbrasil.org/ 
SOCIAL MANIFESTATIONS AND NEW MEDIA: the construction of a counter-hegemonic culture

\section{Paulo Rodrigues Gajanigo Rogério Ferreira de Souza}

The article analyzes some social protests that have appeared around the world from 2008, especially in Egypt, Spain, USA, Chile and Brazil. Our interest is in the impact, on these events, of the use of social networks, already fairly inserted in a context of intense mediation in communication between protesters and public opinion in general. We analyze two aspects: the impact on the organization of these movements and more central use of images as a form of communication. With a view to identify new points, more than deeply analyze them, indicate that there are interesting possibilities for counter-hegemonic struggle from the extensive and intensive use of social media, which is given by the search for radical democracy and critical use of images.

KEYworDs: Internet. Social media. Hegemony. Social movements. Policy.

\section{MANIFESTATIONS SOCIALES ET NOUVEAUX MÉDIAS: la construction d'une culture contre- hégémonique}

\author{
Paulo Rodrigues Gajanigo \\ Rogério Ferreira de Souza
}

Cet article analyse quelques manifestations sociales qui ont eu lieu dans le monde à partir de 2008, tout spécialement en Égypte, en Espagne, aux États-Unis, au Chili et au Brésil. Notre centre d'intérêt se situe au niveau de l'impact créé par l'utilisation des réseaux sociaux dans ces manifestations déjà suffisamment insérées dans un contexte d'intense médiation de ces réseaux pour la communication entre les manifestants et l'opinion publique en général. L'analyse porte sur deux aspects: l'impact au niveau de l'organisation de ces mouvements et l'utilisation chaque fois plus centrale des images comme moyen de communication. Dans l'intérêt d'identifier des éléments nouveaux plus que d'en approfondir l'analyse, nous signalons qu'il y a des possibilités intéressantes de lutte contre-hégémonique grâce à l'utilisation intensive des médias sociaux, auxquels on fait appel en vue d'une démocratie radicale et pour l'utilisation critique de l'image.

Mots-CLÉs: Internet. Médias sociaux. Hégémonie. Mouvements sociaux. Politique.

Paulo Rodrigues Gajanigo - Doutor em Ciências Sociais pela Universidade do Estado do Rio de Janeiro (UERJ); professor adjunto do departamento de Ciências Sociais da Universidade Federal Fluminense (UFF); líder do Núcleo de Estudos da Cultura no Capitalismo Tardio; e membro do Núcl6eo Interdisciplinar de Estudos e Pesquisas sobre Marx e Marxismo (Niep-Marx). Publicou artigos sobre teoria social, antropologia, marxismo e lutas sociais.

Rogério Ferreira de Souza - Doutor em Ciências Sociais pela Universidade do Estado do Rio de Janeiro (UERJ); professor adjunto do Programa de Pós-graduação em Sociologia do Instituto Universitário de Pesquisas do Rio de Janeiro (IUPERJ-UCAM) e coordenador do Laboratório de Estudos da Cidade e Cultura, IUPERJ-UCAM (LECC), junto ao CNPq. Publicou artigos na área de memória social, favela e lutas sociais urbanas, cultura e hegemonia. Organizou os Livros: Cultura Memória e Poder: diálogos interdisciplinares (Eduerj-Faperj, 2013); Sociedade e Perspectiva: cultura, conflito e identidade (Gramma Editora - IUPERJ, 2012). Publicou, em coautoria, a obra Deserdados: dimensão das desigualdades sociais (DeLetra/H.P. Comunicações, 2007). Atualmente, desenvolve a pesquisa "Construção da Memória Coletiva em um espaço militarizado: região portuária do Rio de Janeiro”, financiado pela Faperj. 